\title{
Forest fragmentation shapes the alpha-gamma relationship in plant diversity
}

\author{
Almoussawi Ali ${ }^{1,2}$, Lenoir Jonathan ${ }^{1,{ }^{*}}$, Jamoneau Aurélien ${ }^{1,3}$, Hattab Tarek ${ }^{1,4}$, Wasof Safaa 1,5, \\ Gallet-moron Emilie 1, Garzon-lopez Carol X. 1, 6, Spicher Fabien ${ }^{1}$, Kobaissi Ahmad ${ }^{2}$, \\ Decocq Guillaume ${ }^{1}$, Collins Beverly
}

1 Unité de Recherche "Ecologie et Dynamique des Systèmes Anthropisés" EDYSAN UMR CNRS 7058 , Université de Picardie Jules Verne Amiens ,France

${ }^{2}$ Applied Plant Biotechnology Laboratory Life and Earth Sciences Department Faculty of Sciences Lebanese University Beirut ,Lebanon

${ }^{3}$ Aquatic Ecosystems and Global Changes Research Unit, IRSTEA ,Cestas ,France

${ }^{4}$ UMR MARBEC ,Institut Français de Recherche pour l'Exploitation de la Mer Sète ,France

${ }^{5}$ Department of Environment, Forest \& Nature Lab (ForNaLab) Ghent University ,Melle-

Gontrode ,Belgium

${ }^{6}$ Ecology and Plant Physiology group (Ecofiv), Universidad de los Andes Bogotá, Colombia

* Corresponding author : Jonathan Lenoir, email address : jonathan.lenoir@u-picardie.fr

\begin{abstract}
:
Questions

Forest fragmentation affects biodiversity locally ( $\alpha$ diversity) and beyond - at relatively larger scales $(\gamma$ diversity) - by increasing dispersal and recruitment limitations. Yet, does an increase in fragmentation affect the relationship between $\alpha$ and $y$ diversity and what can we learn from it?

Location

Northern France.

Methods We surveyed 116 forest patches across three fragmentation levels: none (continuous forest); intermediate (forest patches connected by hedgerows); and high (isolated forest patches). Plant species richness of both forest specialists and generalists was surveyed at five nested spatial resolutions across each forest patch: $1 \mathrm{~m} 2 ; 10 \mathrm{~m} 2 ; 100 \mathrm{~m} 2 ; 1,000 \mathrm{~m} 2$; and total forest patch area. First, we ran log-ratio models to quantify the $\alpha-\gamma$ relationship. We did that separately for all possible combinations of fragmentation level (none vs intermediate vs high) $\times$ spatial scale (e.g., $\alpha-1 \mathrm{~m} 2$ vs $\mathrm{y}-10 \mathrm{~m} 2$ ) $\times$ species type (e.g., $\alpha$-specialists vs $\gamma$-specialists). We then used linear mixed-effects models to analyze the effect of fragmentation level, spatial scale, species type and all two-way interaction terms on the slope coefficient extracted from all log-ratio models.
\end{abstract}


Results

We found an interaction effect between fragmentation level and species type, such that forest specialists shifted from a linear (i.e., proportional sampling) to a curvilinear plateau (i.e., community saturation) relationship at low and high fragmentation, respectively, while generalists shifted from a curvilinear to a linear pattern.

\section{Conclusions}

The impact of forest fragmentation on the $\alpha-\gamma$ relationship supports generalist species persistence over forest specialists, with contrasting mechanisms for these two guilds. As fragmentation increases, forest specialists shift from proportional sampling towards community saturation, thus reducing a diversity likely due to dispersal limitation. Contrariwise, generalists shift from community saturation towards proportional sampling, thus increasing a diversity likely due to an increase in the edge:core ratio. To ensure long-term conservation of forest specialists, one single large forest patch should be preferred over several small ones.

Keywords : agricultural landscapes, alpha diversity, anthropogenic disturbances, community assembly, dispersal limitations, gamma diversity, habitat conservation strategies, habitat fragmentation, localregional richness relationship, metacommunity dynamics 


\section{INTRODUCTION}

Habitat loss and fragmentation (i.e. the breakdown of large and contiguous habitats into smaller and more isolated patches) is widely acknowledged as a major cause of biodiversity loss (Wilcox \& Murphy 1985; Tilman 2004). Many empirical and theoretical studies have investigated the effects of habitat loss and fragmentation on species richness at different spatial scales from local (i.e. $\alpha$-diversity) to large (i.e. $\gamma$-diversity) scale (Riitters et al. 2000; Fahrig 2013; Rybicki \& Hanski 2013; Carrara et al. 2015; Hanski 2015; Valdés et al. 2015; Baynes et al. 2016). A decrease in habitat patch size results in lower species richness due to both direct and stochastic areadependent extinction (Pimm et al. 1988; Few et al. 2004). Increased habitat patch isolation magnifies dispersal limitations, thereby impeding metacommunity processes (e.g. rescue and mass effects; Leibold et al., 2004) and ultimately reducing regional species richness first (Cornell \& Lawton, 1992) before reducing local species richness of all habitat patches (Jamoneau, Chabrerie, Closset-Kopp, \& Decocq, 2012). Moreover, the increase in the edge:core ratio following fragmentation alters habitat quality, which has been shown to be particularly detrimental to habitat specialists (Mortelliti et al. 2011). Per contra, generalist species already inhabiting the habitat patches or originating from the surrounding landscape may benefit from an increase in the edge:core ratio, thereby altering species richness within the habitat patches (Vandermeer \& Carvajal 2001; Hanski 2015). Habitat fragmentation per se (i.e. the breaking apart of habitat after controlling for habitat loss) (Fahrig 2003) and management of the landscape matrix may thus alter the relationship between $\alpha$ - and $\gamma$-diversity (sensu Belote, Sanders, \& Jones, 2009; Cornell \& Lawton, 1992; Starzomski, Parker, \& Srivastava, 2008). But surprisingly, how fragmentation impacts this $\alpha \sim \gamma$ relationship - and potentially decouples $\alpha$ - and $\gamma$-diversity - has received little attention so far.

Local species assemblages result from the interaction between local processes (e.g. competition, disturbance) and processes operating at broad scales (e.g. dispersal) (Ricklefs 1987). The relative importance of these two processes and the spatial scale at which they operate are commonly investigated by regressing $\alpha$ - against $\gamma$-diversity (Harrison \& Cornell, 2008; He, Gaston, Connor, \& Srivastava, 2005; Hillebrand \& Blenckner, 2002; Leibold et al., 2004), hereafter referred as the $\alpha \sim \gamma$ relationship (AGR). A positive linear relationship indicates that the local community proportionally samples the set of species available at a larger spatial extent (i.e. the number of species present in a larger area determines the local community: $\alpha$ - and $\gamma$-diversity 
are coupled), whilst a curvilinear-plateau relationship reflects community saturation (i.e. local species interactions limit the number of species that can locally coexist: $\alpha$-and $\gamma$-diversity are decoupled) (Cornell \& Lawton, 1992; Srivastava et al., 2008). However, these patterns have been shown to depend upon environmental severity/stress, with community saturation being predominant under both benign and severe environmental conditions, while proportional sampling dominates under intermediate positions along the environmental severity gradient (Michalet et al., 2015). Since fragmentation can be considered an edge-initiated disturbance impacting environmental conditions, we might expect a similar influence of fragmentation on the AGR. Moreover, the AGR may also change in the course of forest succession, with pseudo-saturation (sensu Lawton \& Strong (1981)) in early stages due to the quick colonization of good dispersers, unsaturation at intermediate stages and saturation in late-successional stages following competitive exclusion (Srivastava et al. 2008).

Forest patchiness is not only the result of fragmentation per se, but also the result of the afforestation of former agricultural lands at different times (Herault \& Honnay 2005). Forest fragmentation may thus not only happen under habitat loss conditions, but also under stable forest cover conditions and even under forest gain (Estreguil et al. 2013). This means that total species richness may even increase as fragmentation increases until the level of fragmentation reaches a threshold that is detrimental to biodiversity as a whole such that total species richness in the landscape decreases. To illustrate this, consider a set of plant communities connected to each other's within a continuous forest matrix (Fig. 1, left panel). Here, forest specialists (FS), i.e. species that are more or less restricted to closed-canopy forest as habitat (Carrara et al. 2015; Valdés et al. 2015; Schlinkert et al. 2016), dominate plant communities. Now, consider a set of plant communities within a fragmented forest surrounded by grasslands but still connected to each other's by linear woody elements (e.g. hedgerows) (Fig. 1, central panel). Then, forest generalists (FG), i.e. species that prefer forest edges and clearings but may survive closed forest conditions (Valdés et al. 2015), are likely to enter the forest patches and co-occur with forest specialists, thereby increasing the number of species co-occurring within the same forest patches compared with the situation in the non-fragmented forests. Finally, if we disconnect forest patches and intensify agricultural practices in the surrounding landscape (Fig. 1, right panel), we expect a negative effect primarily on forest specialists, and ultimately on generalists, by boosting extinction 
cascades and by limiting immigration (Fischer \& Lindenmayer, 2007) so that the total number of species will drop.

The pure effect of fragmentation on the AGR will depend upon the balance between colonization and extirpation events that happen at both the local community scale and the larger forest patch scale. Colonization events of a new plant species not yet occurring within a given forest patch will first happen at the scale of the forest patch before it can happen at the local scale of a given plant community inside the forest patch. Per contra, extirpation events of a given plant species will occur faster at the local community scale than at the entire forest patch scale reflected as richness loss at the $\alpha$-diversity level first, before it can translate to the $\gamma$-diversity level. These processes are predicted to be more pronounced in small forest patches and/or within intensively managed agricultural landscapes because of stronger edge effects (e.g. increased light and nutrient levels) which favor generalist plant species at the expense of forest plant specialists (Bossuyt, Heyn, \& Hermy, 2000; Michalet et al., 2015; He et al., 2005). Based on these considerations, we propose separate research hypotheses for forest specialists and generalists regarding the impact of forest fragmentation on the AGR (Fig. 1). As the level of fragmentation increases, we hypothesize a shift from proportional sampling and stochastic selection (i.e. $\alpha$-diversity is coupled to $\gamma$-diversity and increases linearly as $\gamma$-diversity increases) to more deterministic community saturation due to competition (i.e. $\alpha$-diversity is decoupled from $\gamma$-diversity and reaches a threshold as $\gamma$-diversity increases) for forest specialists (see before last row in Fig. 1) while the opposite pattern is expected for generalists (see last row in Fig. 1). In addition to this interaction effect between the fragmentation level and species type, we also assume different shapes of AGR for specialists and generalists depending on the difference in spatial resolution between $\alpha$ - and $\gamma$-diversity, with community saturation more likely to occur when this difference is large (Loreau 2000). To test these research hypotheses, we used the most recent scientific advances to assess the AGR (SzavaKovats, Ronk, \& Pärtel 2013) of both forest specialists and generalists at several spatial resolutions and across several landscapes in northern France (Hauts-de-France), differing in the level of forest fragmentation, i.e. from non- (fake patches within a forest matrix), to semi- (small, connected patches within a matrix of grasslands) and highly-fragmented (small, isolated patches within a matrix of crop fields) systems. Results from this study will have important implications for landscape planning and biodiversity conservation, notably to preserve forest specialist species which are also the most threatened species in a context of forest fragmentation and management intensification of agricultural landscapes. 


\section{MATERIALS AND METHODS}

\section{Study area}

The study area is located in northern France (N49 $25^{\prime}-50^{\circ} 11^{\prime}$; E1 ${ }^{\circ} 52^{\prime}-3^{\circ} 55^{\prime}$; alt. from 60 to 220 m) (Fig. 2). The climate is oceanic with a mean annual temperature of $10^{\circ} \mathrm{C}$ and total annual rainfall of $700 \mathrm{~mm}$. The geological substrate is dominated by Cretaceous chalks, usually covered by Quaternary loess. The study region is dominated by croplands, intensively cultivated for cereals, rapeseed and sugar beet.

\section{Study design and vegetation survey}

We selected three replicates of $5 \mathrm{~km} \times 5 \mathrm{~km}$ landscape windows for each of the three studied types of landscape covering a contrasted gradient of forest fragmentation from non-fragmented forests (NF) to "openfield" landscapes or highly-fragmented forests (HF) throughout "bocage" landscapes or semi-fragmented forests (SF). The three SF windows consist in small forest patches embedded in a grassland-dominated matrix and connected by hedgerow while the three HF windows consist of small, isolated forest patches surrounded by intensively cultivated croplands. In each of these six landscape windows, we randomly selected 15 forest patches with sizes and shapes allowing us to set up a $1000 \mathrm{~m}^{2}$ quadrat at the center of the forest patch so that the closest forest edge was located at a minimum distance of $10 \mathrm{~m}$. Whenever a window had less than 15 forest patches meeting these criteria, several non-overlapping quadrats (two to four) were arranged within the same large forest patch. For the three NF windows, we created virtual forest patches that mimicked the number, size and shape of the true forest patches found in the six other landscape windows (see Jamoneau, Chabrerie, Closset-Kopp, \& Decocq, (2012) for more details on how virtual forest patches were delineated in the landscape). A total of 135 quadrats ( 9 windows $\times 15$ quadrats) were installed across 116 forest patches, including 39, 36 and 41 forest patches in NF, SF and HF systems, respectively (see raw data in Appendix S1). Note that some landscape windows had less than 15 forest patches of sufficient size $\left(1000 \mathrm{~m}^{2}\right)$. In this case, we used the largest forest patches available within the focal landscape window to set up several quadrats of $1000 \mathrm{~m}^{2}$ within the same forest patch. Yet, because it happened only little (ca. $10 \%$ of the case), we did not account for this limited pseudo-replication issue of having at most 4 quadrats of 1000 $\mathrm{m}^{2}$ each (this case happened only once) belonging to the same very large patch ( $>100 \mathrm{ha}$ ).

Between 2007 and 2008, all 116 forest patches were visited twice, in spring (April-May) and in summer (June-September): we walked along parallel transects located $10 \mathrm{~m}$ apart from 
each other to record all vascular plant species. We thus obtained a value of species richness per forest patch, i.e. patch-scale diversity. In addition to patch-scale diversity, specific floristic surveys were carried out at four nested spatial resolutions within each of the 135 quadrats of $1000 \mathrm{~m}^{2}$, using a logarithmic nested-plot design (see Fig. 1c in (Wasof et al. 2018)): $1 \mathrm{~m}^{2} ; 10 \mathrm{~m}^{2} ; 100 \mathrm{~m}^{2}$; and $1000 \mathrm{~m}^{2}$.

We focused on vascular plant species occurring within the herbaceous layer (height $<1 \mathrm{~m}$ ) solely as it better reflects spontaneous vegetation than in the shrub (height from 1 to $8 \mathrm{~m}$ ) and tree (height $>8 \mathrm{~m}$ ) layers which are more dependent on forest management practices. Note, however, that tall individuals of herb, fern, sedge or grass species which height exceeded the 1-m limit of the herbaceous layer were counted as part of the herbaceous layer. Intraspecific taxa (e.g. subspecies picra and pratensis of Cardamine pratensis) and taxonomic agglomerates (e.g. Rubus fruticosus agg., Taraxacum officinale agg.) were treated as single species. Finally, each of the 175 herbaceous plant species recorded across our study area was classified as either a forest specialist $(\mathrm{FS}: \mathrm{n}=43$ ) or a forest generalist (FG: $\mathrm{n}=132$ ) (Appendix S2) (Oberdorfer 1957).

\section{Patch characteristics, habitat quality and the proportion of forest within the landscape}

To correct for the effects of patch characteristics (area, length and age), habitat quality (soil and light conditions) and the amount of habitat around the focal forest patch (proportion of forest habitat within the landscape) on the AGR, we prepared several variables (Appendix S3) to be included as covariates in all the log-ratio models we ran (see next subsection entitled "Data analysis"). Including these covariates in the log-ratio models allowed us to determine the shape of the AGR for different levels of fragmentation, scale and species type, but independently from potential confounding effects due to differences in patch size, patch age, patch quality and forest loss or gain in the surrounding landscape (here we are interested in the pure effect of habitat fragmentation and not in habitat loss or gain which may confound with habitat fragmentation per se).

\section{Data analysis}

To assess the shape of the AGR, we not only considered FS and FG separately but we also considered the total diversity (FS+FG), thus leading to three possible relationships among species types that we tested: (1) $\alpha_{\mathrm{FS}+\mathrm{FG}} \sim \gamma_{\mathrm{FS}+\mathrm{FG}}$; (2) $\alpha_{\mathrm{FS}} \sim \gamma_{\mathrm{FS}}$; and (3) $\alpha_{\mathrm{FG}} \sim \gamma_{\mathrm{FG}}$. Hence, we assessed the shape of the AGR for all possible combinations of species type relationship $\left(\alpha_{\mathrm{FS}} \sim \gamma_{\mathrm{FS}}, \alpha_{\mathrm{FG}} \sim \gamma_{\mathrm{FG}}\right.$, 
$\left.\alpha_{\mathrm{FS}+\mathrm{FG}} \sim \gamma_{\mathrm{FS}+\mathrm{FG}}\right) \times$ fragmentation level $(\mathrm{NF}, \mathrm{SF}, \mathrm{HF}) \times$ spatial scale (e.g. $\left.\alpha-1 \mathrm{~m}^{2} v s . \gamma-10 \mathrm{~m}^{2}\right)$, while controlling for the effect of several covariates (Appendix S3). Like in Belote et al. (2009), we considered species richness of any spatial resolution nested within a larger one as $\alpha$-diversity relative to the species richness in the larger plot which we considered as $\gamma$-diversity. This leads to a total of ten combinations of nested spatial scales: (1) $\alpha-1 \mathrm{~m}^{2} v s . \gamma-10 \mathrm{~m}^{2}$; (2) $\alpha-1 \mathrm{~m}^{2} v s . \gamma-100 \mathrm{~m}^{2}$; (3) $\alpha-1 \mathrm{~m}^{2}$ vs. $\gamma-1000 \mathrm{~m}^{2}$; (4) $\alpha-1 \mathrm{~m}^{2}$ vs. $\gamma$-total; (5) $\alpha-10 \mathrm{~m}^{2}$ vs. $\gamma-100 \mathrm{~m}^{2}$; (6) $\alpha-10 \mathrm{~m}^{2}$ vs. $\gamma-1000 \mathrm{~m}^{2}$; (7) $\alpha-10 \mathrm{~m}^{2}$ vs. $\gamma$-total; (8) $\alpha-100 \mathrm{~m}^{2}$ vs. $\gamma-1000 \mathrm{~m}^{2}$; (9) $\alpha-100 \mathrm{~m}^{2}$ vs. $\gamma$-total; and (10) $\alpha-1000 \mathrm{~m}^{2}$ vs. $\gamma$ total.

To assess the shape of the AGR, we ran a multiple-regression version (Equation 1) (see Appendix S4 for more details) of the log-ratio model proposed by Szava-Kovats, Zobel, \& Pärtel (2012) for each landscape window separately, for a given nested spatial scale combination (e.g. $\alpha$ $1 \mathrm{~m}^{2} v s . \gamma-10 \mathrm{~m}^{2}$ ) and for a given combination of species type relationship (e.g. $\alpha_{\mathrm{FS}} \sim \gamma_{\mathrm{FS}}$ ). This makes a total of 270 log-ratio models: three fragmentation levels $\times$ three replicates per fragmentation level $\times$ ten nested spatial scales $\times$ three species type relationships. For each of these 270 possible combinations, we ran a linear regression with $\log (\alpha /(\gamma-\alpha))$ as the response variable and $\log (\gamma)$ as the main predictor variable while accounting for several covariates: patch area, length and age; soil $p H, C: N$ and $P$; light conditions (SCA); and the proportion of forest within a 500-m radius (for 500) (see Appendix S3 for more information on the covariates). All covariates were standardized prior to analysis, i.e. the value for each variable was subtracted from its mean and divided by its standard deviation (Schielzeth 2010).

$$
\ln \left(\frac{\alpha}{\gamma-\alpha}\right) \sim \ln (\gamma)+\text { area }+ \text { length }+ \text { age }+p H+C: N+P+\text { light }+ \text { for }_{500}
$$

Equation 1

Once the $270 \log$-ratio models were fitted, we extracted the slope coefficient of $\log (\gamma)$, which provides a quantitative estimate of the shape of the AGR. Then, we split the 270 slope coefficients into two different datasets: (1) $\alpha_{\mathrm{FS}+\mathrm{FG}} \sim \gamma_{\mathrm{FS}+\mathrm{FG}}(\mathrm{n}=90)$ and (2) $\alpha_{\mathrm{FSorFG}} \sim \gamma_{\mathrm{FSorFG}}(\mathrm{n}=$ 180). For both datasets, we built several candidate models (i.e. step 2 in our analyses) to explain the observed variation in the slope coefficient (i.e. the response variable). As explanatory variables, we tested the effect of fragmentation level (frag: NF, SF, HF), spatial scale (scale: 1, 2, $3,4)$, species type ( $s p$ : FS vs. FG) as well as all possible two-way interactions between all three 
variables. More specifically, we tested nine candidate models: (1) slope $\sim$ frag $+s p$; (2) slope $~$ frag + scale; (3) slope $\sim$ frag $\times$ sp; (4) slope $\sim$ frag $\times$ scale; (5) slope $\sim$ frag + scale + sp; (6) slope $\sim$ frag $\times$ sp + scale $;(7)$ slope $\sim$ frag $\times$ scale $+s p ;(8)$ slope $\sim$ frag + scale $\times$ sp, and (9) slope $\sim$ frag $\times$ scale $\times s p$. Spatial scale was here treated as a semi-quantitative (ordinal) variable measuring the nestedness factor between $\alpha$ - and $\gamma$-diversity (e.g. $\alpha-1 \mathrm{~m}^{2} v$ s. $\gamma-10 \mathrm{~m}^{2}, \alpha-1 \mathrm{~m}^{2} v s . \gamma$ $100 \mathrm{~m}^{2}, \alpha-1 \mathrm{~m}^{2} v s . \gamma-1000 \mathrm{~m}^{2}$ and $\alpha-1 \mathrm{~m}^{2} v s$. total patch area have nestedness factor of $1,2,3$ and 4 , respectively). Note that for the first dataset $\left(\alpha_{\mathrm{FS}+\mathrm{FG}} \sim \gamma_{\mathrm{FS}+\mathrm{FG}}\right)$, which focuses on all herbaceous plants without distinguishing between specialists and generalists, we could only test the effect of fragmentation level, spatial scale and the interaction between the two, thus leading to two candidate models only (slope $\sim$ frag + scale vs. slope $\sim$ frag $\times$ scale). To run our candidate models with the slope of the log-ratio models as the response variable, we used a linear mixed-effects modelling (LMM) approach with the three replicates per fragmentation level as well as the ten combinations of nested spatial resolutions as random intercept terms. To compare candidate models with nested fixed effects (but with the same random structure), we used maximum likelihood (ML) estimation instead of restricted maximum likelihood (REML) (Zuur et al. 2009). As the best candidate model, we selected the model with the smallest Akaike information criteria (AIC) and rerun the selected best model using REML for final inference and reporting of the models' parameters (Zuur et al. 2009).

All statistical analyses were performed using the "lme4" (Bates et al. 2015), "nlme" (Pinheiro, 2002), “broom” (Robinson 2014), "MuMIn” (Grueber et al. 2011), "glmm” (Green \& MacLeod 2016), “mvtnorm" (Genz \& Bretz 2009), "digest" (Genz \& Bretz 2009) and "Matrix" (Fiske \& Chandler 2011) packages in the R software environment version 3.4.1 (R Core Team 2017).

This article is protected by copyright. All rights reserved 


\section{RESULTS}

In general, we found that the slope parameter of the $\alpha \sim \gamma$ relationship (AGR) of herbaceous forest plants is close to zero (mean \pm standard deviation: $-0.281 \pm 0.85 ; \mathrm{n}=270$ ) and does not significantly differ from zero ( $\mathrm{p}$-value $=0.1185$, see Appendix S5 for detailed 'one sample t-test' for the distribution of the 270 slope values $\&$ detailed 'Anova' outputs for all the studied candidate models), suggesting linear patterns (Type I) to predominate (see Appendix S6). Focusing on the $\log$-ratio models relating $\alpha$ to $\gamma$ diversity of all forest species, combining forest specialists with generalists $\left(\alpha_{\mathrm{FS}+\mathrm{FG}} \sim \gamma_{\mathrm{FS}+\mathrm{FG}}\right)(-0.11 \pm 0.22)(\mathrm{n}=90)($ Fig. 3a), the best model $($ slope $\sim$ frag + scale $)$ showed a significant effect of fragmentation but no effect of spatial scale on the shape of the AGR (Table 1, see Appendix S7 for the output of other candidate models). Accordingly, the AGR shifted from a linear (Type I) to a curvilinear (Type II) pattern as the level of fragmentation increased (Fig. 3a and Fig. 4a). For the log-ratio models relating $\alpha$ to $\gamma$ diversity of either forest specialists $\left(\alpha_{\mathrm{FS}} \sim \gamma_{\mathrm{FS}}\right)(-0.574 \pm 1.06)(\mathrm{n}=90)($ Fig. $3 b)$ or generalists $\left(\alpha_{\mathrm{FG}} \sim \gamma_{\mathrm{FG}}\right)(-0.188 \pm 0.789)$ $(\mathrm{n}=90)$ (Fig. 3c), we found a significant interaction effect between fragmentation and species type but no effect of spatial scale (best model: slope $\sim$ frag $\times s p$ ) (Table 1, see Appendix S7 for the output of other candidate models). The AGR of forest specialists showed a shift from Type I to Type II curves as the fragmentation level increased from non-fragmented to highly-fragmented systems, while the AGR of forest generalists showed the complete opposite pattern; shifting from Type II to Type I as the fragmentation level increased (Appendix S6 and Figs. 4b and 4c).

This article is protected by copyright. All rights reserved 


\section{DISCUSSION}

Even after accounting for forest patch characteristics, habitat quality and the proportion of forest habitat within the landscape, the shape of the $\alpha \sim \gamma$ relationship (AGR) summarized by the slope parameter of the log-ratio model still varies a lot (Fig. 3), albeit proportional sampling seems predominant. This variability underlies complex interplays between the level of forest fragmentation and the degree of herbaceous species specialization for forests (Fig. 4). Although the AGR only describes patterns, these patterns may underlie important ecological processes (e.g. community saturation suggests biotic interactions or dispersal limitations) (He et al. 2005) that differ between forest specialists and generalists in response to forest fragmentation. Below, we discuss our main findings in light of the potential underlying ecological processes and their relevance for biodiversity conservation and landscape planning.

\section{Proportional sampling predominates but it hides complex interactions}

In general, we found a predominance of linear (i.e. proportional sampling or Type I) AGR (Appendix S6), irrespective of the spatial resolution considered (Table 1), thus supporting former conclusions on the importance of regional processes in shaping local species richness (Cornell \& Harrison, 2013; Harrison \& Cornell, 2008). Yet, we also found that the prevalence of community saturation was the highest under some circumstances: for forest specialists within highlyfragmented systems and for generalist species within non-fragmented systems. This supports more recent findings on the relative importance of local processes under some environmental circumstances (Michalet et al., 2015). The critical analyses of Gonçalves-Souza, Romero, and Cottenie (2013) and Szava-Kovats et al., (2013), who used the log-ratio method to reanalyze data from 113 and 100 published datasets, respectively, found no prevalence of either unsaturated or saturated communities. In fact, these two meta-analyses concluded that a large proportion of studies produced no discernible patterns (i.e. intermediate and indeterminate cases). Accordingly, our results also show that intermediate and indeterminate patterns between Type I and Type II can contribute a significant proportion in the observed AGR, being predominant in semi-fragmented systems (Appendix S6). Overall, this suggests a gradual shift from either proportional sampling to community saturation (i.e. for forest specialists) or the opposite (i.e. for generalists) as the fragmentation level increases, thus supporting our initial hypothesis of a complex interplay between forest fragmentation and species type (Fig. 1).

\section{Forest fragmentation negatively impacts forest specialists}

This article is protected by copyright. All rights reserved 
Supporting our initial hypothesis for forest specialists (Fig. 1), we found a shift from proportional sampling within non-fragmented systems towards community saturation within highly-fragmented systems (i.e. isolated forest patches within a highly-disturbed matrix of croplands) (Fig. 4b), irrespective of the spatial resolution at which $\alpha$ and $\gamma$ diversity are measured (Table 1). Within non-fragmented forests, habitat quality is optimal and thus dispersal and recruitment limitations are low for forest specialists. Hence, a proportional increase in the number of forest specialist species co-occurring locally can be observed with the increasing number of forest specialists available from a relatively larger area.

Per contra, highly fragmented forests negatively affect the local establishment of forest specialists, thus decreasing the slope value of the log-ratio model towards community saturation. First, this may reflect a relative increase in competitive exclusion, especially asymmetric competition, when more successful herbaceous plant species gain a progressively greater share of the available resources (Peet \& Christensen 1988). In such systems, small-stature forest herb specialists likely suffer from recruitment and persistence limitations in small and/or recent forest patches, due to increased light and mineral nutrient levels that primarily benefit a few generalist tall forbs, e.g. Rubus fruticosus agg. and Urtica dioica, or creeping woody species e.g. Hedera helix in our study. These species contribute to most of the aboveground biomass of the herb layer competing for light (Ma et al. 2018) and may thus competitively exclude smaller-statured forest specialists (Hermy et al. 1999; Verheyen \& Hermy 2016) and ultimately decrease herbaceous plant species richness relative to non-fragmented forests (Jacquemyn et al., 2001; Ma et al., 2018). This is especially the case along forest edges, which have been suggested efficient physical barriers against the arrival of forest specialists from neighboring patches (Fischer and Lindenmayer, 2007; Pickett et al., 2001).

Second, in highly-fragmented systems, forest patches are not sufficiently connected to allow most forest herbs to disperse among them, since forest herb species are well known for their low dispersal abilities (Verheyen \& Hermy 2001; Vellend et al. 2007). Consistently, we found a tendency towards more forest specialist species accumulating locally as patch age increases (see the effect of covariates from the $\alpha_{\mathrm{FS}} \sim \gamma_{\mathrm{FS}}$ log-ratio models in Appendix S8), as predicted by the species-time relationship (Rosenzweig \& Ziv, 1999) and previous observations in fragmented forests (Jamoneau et al. 2011). In other words, new forest patches are hardly colonized by forest specialists, and it takes even much more time before they spread over the entire forest patch area. Forest specialists within new forest patches thus form scattered founding populations in an 
otherwise generalist-dominated plant community, so that the number of generalists increases faster than the number of forest specialists when increasing the sample area. The observed switch from linear to curvilinear-plateau AGR for forest specialists may thus be explained also in the absence of competitive exclusion (Lawton and Strong, 1981; Mouquet \& Loreau, 2003), simply because only good colonizers and very generalist species with a wide ecological niche can quickly colonize a focal area. A similar pattern was reported for calcareous grasslands, where both the size of the species pool and community age influenced local species richness (Pärtel \& Zobel 1995). At the same time, populations of forest specialists in older patches may be hardly rescued by immigration and hence, be more exposed to stochastic extirpation (Hérault \& Honnay, 2005; Jamoneau et al., 2012), a process potentially contributing to the reported decrease in the slope of the log-ratio model of forest specialists as fragmentation increases.

\section{Forest fragmentation promotes generalist species}

The fact that the number of generalist species co-occurring within forest plant communities tend to increase linearly with the number of generalist species available from a relatively larger area inside highly-fragmented systems is consistent with the idea that anthropogenic disturbances as well as edge effects (i.e. the part of a forest patch which is influenced by the surrounding landscape matrix) imposed by agricultural practices may create more favorable conditions for generalist species (Fischer \& Lindenmayer 2007), at the expense of forest specialists.

Generalist plant species, that are usually fast-colonizers (Brunet et al. 2011), have been shown to decrease in abundance from the edge to the forest interior, whilst the reverse pattern applied to slow colonizers such as ancient forest plant species (Hardiman et al. 2013). This niche partitioning along edge-core gradients in forests can be explained by the well-known trade-off between survival in deep shade and growth in full light (Hubbell \& Foster 1992; Coomes et al. 2009), with the successful penetration of generalists into the forest interior usually limited by unfavorable light conditions (Harper et al., 2005; Hérault \& Honnay, 2005). Edge effects have been reported to extend 20 to $50 \mathrm{~m}$ (Hérault \& Honnay, 2005; Murcia, 1995) and even 100 to 200 m (Laurance et al. 2008; Hardiman et al. 2013) towards the forest interior. In our studied fragmented systems, this means that, to a certain extent, almost all forest patches are edge habitats rather than true forest interior habitats. Generalist species originating from the surrounding landscape are able to colonize edges of forest patches and subsequently migrate towards the patch interior, according to the so-called "biodiversity spillover effect" (Brudvig et al. 2009; Araujo Calçada et al. 2013). This spillover effect is likely more effective in highly-fragmented systems 
where forest patches are more exposed to lime and fertilizer leachates from adjacent croplands, compared to forest patches in the semi-fragmented systems. Moreover, nutrient-rich forests are accompanied by a range of light conditions which is greater than the range of light conditions available in nutrient-poor forests (Coomes et al. 2009), explaining why forests on fertile soils are more species-rich than their counterparts on nutrient-poor soils (Cornwell \& Grubb 2003; Laanisto et al. 2008; Coomes et al. 2009).

In contrast with fragmented systems, continuous forest patches in the non-fragmented system represent true forest interior habitats without edge effects, which offer light and soil conditions that are less suitable for generalist species (Jules 1998). The shift from proportional sampling of generalists within highly fragmented systems towards community saturation within non-fragmented systems (Fig. 4c) can thus be explained by the absence of biodiversity spillover effect due to the absence of edge effects. We thus conclude that the shape of the AGR for generalists relates to the spatial distribution of generalist species within the forest patch rather than to biotic interactions: regular over the entire patch, partitioned along the edge-core gradient and randomly clustered in highly-, semi- and non-fragmented systems, respectively.

\section{Conclusion}

Our results suggest that forest fragmentation affects the $\alpha \sim \gamma$ relationship by favoring generalist species over forest specialists (Karlson \& Cornell 2002; Myers \& Harms 2009). The striking different responses to forest fragmentation between forest specialists and generalists suggests that community assembly rules operate differently for these two guilds. In large and ancient forests, high quality habitat combined with the lack of fragmentation allows forest specialists to dominate the herb layer. Conversely, small and/or new forest patches isolated within a matrix of intensively cultivated landscapes are not only hardly colonized by dispersal-limited forest specialists, but also exposed to intense edge effects that allow generalist species to preempt space and resources and subsequently prevent forest specialists from establishment/persistence.

These findings have strong implications for biodiversity conservation and landscape planning, and fuel the single large or several small (SLOSS) debate (Diamond 1975; Simberloff \& Abele 1982) by suggesting contrasting impact of forest fragmentation on the community assembly of forest specialists and generalists. Computing the $\alpha \sim \gamma$ relationship across a given landscape and separately between forest specialists and generalists will help to quickly visualize and assess the functioning state, and thus the quality, of forest metacommunities within the focal landscape. This may serve as a diagnostic tool to guide landscape management actions for biodiversity 
conservation, depending on whether one aims at maximizing the total number of species or at maximizing the conservation of patrimonial species such as forest specialists. At a regional scale, the "several small" strategy would indeed increase total species richness per forest patch (Yaacobi et al. 2007; Fahrig 2013), but at the expense of forest specialists by maximizing the proportion of generalist species, whilst the "single large" strategy would primarily benefit forest specialists, that are also the most threatened species in a context of global environmental changes and management intensification of landscapes. Preserving the biggest, most ancient forest patches and maintaining/restoring connectivity between these patches should thus be encouraged in agricultural landscapes to ensure the long-term conservation of forest plant biodiversity, and its associated ecosystem services.

\section{ACKNOWLEDGEMENTS}

We greatly acknowledge the "Clover ME" for funding AA's PhD thesis. We wish to thank R. Saguez, C. Mallet, V. Garcia, L. Bocher-Leroy, G. Ingelaere, F. Bartowiack, C.-E. Bernard, S. Delormel, J. Fatus and J. Demarcq for their contribution to field surveys. This study was part of the METAFOR research project funded by the Conseil Régional de Picardie.

\section{AUTHOR CONTRIBUTIONS}

GD and JL conceived the study and the analytical framework; AJ collected the field data; AA TH, JL, CXGL and SW ran the statistical analyses; EGM conducted all GIS analyses. AA, JL and GD led the writing; all co-authors discussed the results, provided feedback and commented on the initial versions of the manuscript. 


\section{REFERENCES}

Araujo Calçada, E., Closset-Kopp, D., Gallet-Moron, E., Lenoir, J., Rêve, M., Hermy, M., \& Decocq, G. 2013. Streams are efficient corridors for plant species in forest metacommunities. Journal of Applied Ecology 50: 1152-1160.

Bates, D., Mächler, M., Bolker, B., \& Walker, S. 2015. Fitting Linear Mixed-Effects Models Using Ime4. Journal of Statistical Software 67: 1-48.

Baynes, J., Herbohn, J., Chazdon, R.L., Nguyen, H., Firn, J., Gregorio, N., \& Lamb, D. 2016. Effects of fragmentation and landscape variation on tree diversity in post-logging regrowth forests of the Southern Philippines. Biodiversity and Conservation 25: 923-941.

Belote, R.T., Sanders, N.J., \& Jones, R.H. 2009. Disturbance alters local-regional richness relationships in appalachian forests. Ecology 90: 2940-2947.

Bossuyt, B., Heyn, M., \& Hermy, M. 2000. Concentrating samples estimates a larger seed bank density of a forest soil. Functional Ecology 14: 766-768.

Brudvig, L.A., Damschen, E.I., Tewksbury, J.J., Haddad, N.M., \& Levey, D.J. 2009. Landscape connectivity promotes plant biodiversity spillover into non-target habitats. Proceedings of the National Academy of Sciences 106: 9328-9332.

Brunet, J., Valtinat, K., Mayr, M.L., Felton, A., Lindbladh, M., \& Bruun, H.H. 2011. Understory succession in post-agricultural oak forests: habitat fragmentation affects forest specialists and generalists differently. Forest Ecology and Management 262: 1863-1871.

Carrara, E., Arroyo-Rodríguez, V., Vega-Rivera, J.H., Schondube, J.E., de Freitas, S.M., \& Fahrig, L. 2015. Impact of landscape composition and configuration on forest specialist and generalist bird species in the fragmented Lacandona rainforest, Mexico. Biological Conservation 184: 117-126.

Chabrerie, O., Jamoneau, A., Gallet-Moron, E., \& Decocq, G. 2013. Maturation of forest edges is constrained by neighbouring agricultural land management (M. Zobel, Ed.). Journal of Vegetation Science 24: 58-69.

Coomes, D.A., Kunstler, G., Canham, C.D., \& Wright, E. 2009. A greater range of shadetolerance niches in nutrient-rich forests: An explanation for positive richness-productivity relationships? Journal of Ecology 97: 705-717.

Cornell, H.V., \& Harrison, S.P. 2013. Regional effects as important determinants of local diversity in both marine and terrestrial systems. Oikos 122: 288-297. 
Cornell, H.V., \& Lawton, J.H. 1992. Species Interactions, Local and Regional Processes, and Limits to the Richness of Ecological Communities: A Theoretical Perspective. The Journal of Animal Ecology 61: 1-12.

Cornwell, W.K., \& Grubb, P.J. 2003. Regional and local patterns in plant species richness with respect to resource availability. Oikos 100: 417-428.

Diamond, J.M. 1975. The island dilemma: Lessons of modern biogeographic studies for the design of natural reserves. Biological Conservation 7: 129-146.

Estreguil, C., Caudullo, G., de Rigo, D., \& San-Miguel-Ayanz, J. 2013. Forest Landscape in Europe: Pattern, Fragmentation and Connectivity. EUR - Scientific and Technical Research 25717: 18 pp.

Fahrig, L. 2003. Effects of Habitat Fragmentation on Biodiversity. Annual Review of Ecology, Evolution, and Systematics 34: 487-515.

Fahrig, L. 2013. Rethinking patch size and isolation effects: The habitat amount hypothesis. Journal of Biogeography 40: 1649-1663.

Few, R., Ahern, M., Matthies, F., \& Kovats, S. 2004. Floods, health and climate change: a strategic review. Tyndall Centre Working Paper 138 pp.

Fischer, J., \& Lindenmayer, D.B. 2007. Landscape modification and habitat fragmentation: a synthesis. Global Ecology and Biogeography 16: 265-280.

Fiske, I., \& Chandler, R. 2011. Unmarked: an R package for fitting hierarchical models of wildlife occurrence and abundance. Journal of statistical software 43: 1-23.

Genz, A., \& Bretz, F. 2009. Computation of multivariate normal and t probabilities. Springer Science \& Business Media.

Gonçalves-Souza, T., Romero, G.Q., \& Cottenie, K. 2013. A critical analysis of the ubiquity of linear local-regional richness relationships. Oikos 122: 961-966.

Green, P., \& MacLeod, C.J. 2016. SIMR : an R package for power analysis of generalized linear mixed models by simulation (S. Nakagawa, Ed.). Methods in Ecology and Evolution 7: 493-498.

Grueber, C.E., Nakagawa, S., Laws, R.J., \& Jamieson, I.G. 2011. Multimodel inference in ecology and evolution: challenges and solutions: Multimodel inference. Journal of Evolutionary Biology 24: 699-711.

Hans Jacquemyn, J.B. and M.H. 2001. Forest Plant Species Richness in Small, Fragmented Mixed Deciduous Forest Patches: The Role of Area, Time and Dispersal Limitation 
Author ( $\mathrm{s}$ ): Hans Jacquemyn , Jan Butaye , Martin Hermy Published by: Blackwell Publishing Stable URL : http://www.jsto. Time 28: 801-812.

Hanski, I. 2015. Habitat fragmentation and species richness. Journal of Biogeography 42: 989993.

Hardiman, B.S., Gough, C.M., Halperin, A., Hofmeister, K.L., Nave, L.E., Bohrer, G., \& Curtis, P.S. 2013. Maintaining high rates of carbon storage in old forests: A mechanism linking canopy structure to forest function. Forest Ecology and Management 298: 111-119.

Harper, K.A., Macdonald, S.E., Burton, P.J., Chen, J., Brosofske, K.D., Saunders, S.C., Euskirchen, E.S., Roberts, D.A.R., Jaiteh, M.S., \& Esseen, P.-A. 2005. Edge Influence on Forest Structure and Composition in Fragmented Landscapes. Conservation Biology 19: $768-782$.

Harrison, S., \& Cornell, H. 2008. Toward a better understanding of the regional causes of local community richness. Ecology Letters 11: 969-979.

He, F., Gaston, K.J., Connor, E.F., \& Srivastava, D.S. 2005. The Local-Regional Relationship: Immigration, Extinction, and Scale. Ecology 86: 360-365.

Hérault, B., \& Honnay, O. 2005. The relative importance of local, regional and historical factors determining the distribution of plants in fragmented riverine forests: An emergent group approach. Journal of Biogeography 32: 2069-2081.

Hermy, M., Honnay, O., Firbank, L., Grashof-Bokdam, C., \& Lawesson, J.E. 1999. An ecological comparison between ancient and other forest plant species of Europe, and the implications for forest conservation. Biological Conservation 91: 9-22.

Hillebrand, H., \& Blenckner, T. 2002. Regional and local impact on species diversity - from pattern to processes. Oecologia 132: 479-491.

Hubbell, S.P., \& Foster, R.B. 1992. Nordic Society Oikos Short-Term Dynamics of a Neotropical Forest: Why Ecological Research Matters to Tropical Conservation and Management. Nordic Society Oikos Stable 63: 48-61.

Jamoneau, A., Chabrerie, O., Closset-Kopp, D., \& Decocq, G. 2012. Fragmentation alters betadiversity patterns of habitat specialists within forest metacommunities. Ecography 35: $124-133$.

Jamoneau, A., Sonnier, G., Chabrerie, O., Closset-Kopp, D., Saguez, R., Gallet-Moron, E., \& Decocq, G. 2011. Drivers of plant species assemblages in forest patches among contrasted dynamic agricultural landscapes. Journal of Ecology 99: 1152-1161. 
Jules, E.S. 1998. Habitat fragmentation and demographic change for a common plant: Trillium in old-growth forest. Ecology 79: 1645-1656.

Karlson, R.H., \& Cornell, H.V. 2002. Species richness of coral assemblages: detecting regional influences at local spatial scales. Ecology 83: 452-463.

Laanisto, L., Urbas, P., \& Pärtel, M. 2008. Why does the unimodal species richness-productivity relationship not apply to woody species: a lack of clonality or a legacy of tropical evolutionary history? Global Ecology and Biogeography 17: 320-326.

Laurance, W.F., Laurance, S.G., Ferreira, L. V., Rankin-de Merona, J.M., Gascon, C., \& Lovejoy, T.E. 2008. Biomass collapse in Amazonian forest fragments. Science 278: 1117-1118.

Lawton and strong. 1981. Community Patterns and Competition in Folivorous Insects Author ( s ): J . H . Lawton , D . R . Strong and Jr . Published by: The University of Chicago Press for The American Society of Naturalists Stable URL: http://www.jstor.org/stable/2460635 Accesse. 118: 317-338.

Leibold, M.A., Holyoak, M., Mouquet, N., Amarasekare, P., Chase, J.M., Hoopes, M.F., Holt, R.D., Shurin, J.B., Law, R., Tilman, D., Loreau, M., \& Gonzalez, A. 2004. The metacommunity concept: a framework for multi-scale community ecology: The metacommunity concept. Ecology Letters 7: 601-613.

Loreau, M. 2000. Are communities saturated? On the relationship between $\alpha, \beta$ and $\gamma$ diversity. Ecology Letters 3: 73-76.

Ma, S., Verheyen, K., Props, R., Wasof, S., Vanhellemont, M., Boeckx, P., Boon, N., \& De Frenne, P. 2018. Plant and soil microbe responses to light, warming and nitrogen addition in a temperate forest. Functional Ecology 1-11.

Michalet, R., Maalouf, J.P., Choler, P., Clément, B., Rosebery, D., Royer, J.M., Schöb, C., \& Lortie, C.J. 2015. Competition, facilitation and environmental severity shape the relationship between local and regional species richness in plant communities. Ecography 38: $335-345$.

Mortelliti, A., Amori, G., Capizzi, D., Cervone, C., Fagiani, S., Pollini, B., \& Boitani, L. 2011. Independent effects of habitat loss, habitat fragmentation and structural connectivity on the distribution of two arboreal rodents. Journal of Applied Ecology 48: 153-162.

Mouquet, N., \& Loreau, M. 2003. Community Patterns in Source-Sink Metacommunities. The American Naturalist 162: 544-557. 
Murcia, C. 1995. Edge effects in fragmented forests: implications for conservation. Trends in Ecology \& Evolution 10: 58-62.

Myers, J.A., \& Harms, K.E. 2009. Seed arrival, ecological filters, and plant species richness: a meta-analysis. Ecology Letters 12: 1250-1260.

Oberdorfer, E. 1957. Pflanzensoziologie. Gustav Fischer.

Pärtel, M., \& Zobel, M. 1995. Small-scale dynamics and species richness in successional alvar plant communities Ecography Volume 18, Issue 1. Ecography 18: 83-90.

Peet, R.K., \& Christensen, N.L. 1988. Changes in species diversity during secondary forest succession on the North Carolina Piedmont. Diversity and Pattern in Plant Communities.

Pickett, S.T.A., Cadenasso, M.L., Grove, J.M., Nilon, C.H., Pouyat, R. V, Zipperer, W.C., \& Costanza, R. 2001. U RBAN E COLOGICAL S YSTEMS : Linking Terrestrial Ecological , Physical , and Socioeconomic. Urban Ecosystems. doi: 10.1146/annurev.ecolsys.32.081501.114012

Pimm, S.L., Jones, H.L., \& Diamond, J. 1988. On the Risk of Extinction. The American Naturalist 132: $757-785$.

Pinheiro, J.C. Model building using covariates in nonlinear mixed-effects models.

Ricklefs, R. 1987. Community Diversity: Relative Roles of Local and Regional Processes. Science 235: $167-171$.

Riitters, K., Wickham, J., Neill, R.O., Jones, B., \& Smith, E. 2000. Global-scale patterns of forest fragmentation. Conservation Ecology 4: 3.

Robinson, D. 2014. broom: An R Package for Converting Statistical Analysis Objects Into Tidy Data Frames. arXiv:1412.3565.

Rosenzweig, M.L., \& Ziv, Y. 2001. The echo patterns of species diversity: pattern and process. Ecography 22: 614-628.

Rybicki, J., \& Hanski, I. 2013. Species-area relationships and extinctions caused by habitat loss and fragmentation. Ecology Letters 16: 27-38.

Schielzeth, H. 2010. Simple means to improve the interpretability of regression coefficients. Methods in Ecology and Evolution 1: 103-113.

Schlinkert, H., Westphal, C., Clough, Y., Grass, I., Helmerichs, J., \& Tscharntke, T. 2016. Plant size affects mutualistic and antagonistic interactions and reproductive success across 21 Brassicaceae species. Ecosphere 7: 1-14. 
Simberloff, D., \& Abele, L.G. 1982. Refuge Design and Island Biogeographic Theory: Effects of Fragmentation. The American Naturalist 120: 41-50.

Srivastava, D.S., Starzomski, B.M., \& Parker, R.L. 2008. on the Relationship Between Regional and Local Species Richness: a Test of Saturation Theory. Ecology 89: 1921-1930.

Starzomski, B.M., Parker, R.L., \& Srivastava, D.S. 2008. On The Relationship Between Regional And Local Species Richness: A Test Of Saturation Theory. Ecology 89: 1921-1930.

Szava-Kovats, R.C., Ronk, A., \& Pärtel, M. 2013. Pattern without bias: local-regional richness relationship revisited. Ecology 94: 1986-1992.

Szava-Kovats, R.C., Zobel, M., \& Pärtel, M. 2012. The local-regional species richness relationship: New perspectives on the null-hypothesis. Oikos 121: 321-326.

Tilman, D. 2004. Niche tradeoffs, neutrality, and community structure: A stochastic theory of resource competition, invasion, and community assembly. Proceedings of the National Academy of Sciences 101: 10854-10861.

Valdés, A., Lenoir, J., Gallet-Moron, E., Andrieu, E., Brunet, J., Chabrerie, O., Closset-Kopp, D., Cousins, S.A.O., Deconchat, M., De Frenne, P., De Smedt, P., Diekmann, M., Hansen, K., Hermy, M., Kolb, A., Liira, J., Lindgren, J., Naaf, T., Paal, T., Prokofieva, I., SchererLorenzen, M., Wulf, M., Verheyen, K., \& Decocq, G. 2015. The contribution of patchscale conditions is greater than that of macroclimate in explaining local plant diversity in fragmented forests across Europe. Global Ecology and Biogeography 24: 1094-1105.

Vandermeer, J., \& Carvajal, R. 2001. Metapopulation Dynamics and the Quality of the Matrix. The American Naturalist 158: 211-220.

Vellend, M., Verheyen, K., Flinn, K.M., Jacquemyn, H., Kolb, A., Van Calster, H., Peterken, G., Graae, B.J., Bellemare, J., Honnay, O., Brunet, J., Wulf, M., Gerhardt, F., \& Hermy, M. 2007. Homogenization of forest plant communities and weakening of species-environment relationships via agricultural land use. Journal of Ecology 95: 565-573.

Verheyen, K., \& Hermy, M. 2016. The Relative Importance of Dispersal Limitation of Vascular Plants in Secondary Forest Succession in Muizen Forest, Belgium Author ( $\mathrm{s}$ ): Kris Verheyen and Martin Hermy Published by: British Ecological Society Stable URL: http://www.jstor.org/stable/30. 89: 829-840.

Wasof, S., Lenoir, J., Hattab, T., Jamoneau, A., Gallet-Moron, E., Ampoorter, E., Saguez, R., Bennsadek, L., Bertrand, R., Valdès, A., Verheyen, K., \& Decocq, G. 2018. Dominance of 
individual plant species is more important than diversity in explaining plant biomass in the forest understorey. Journal of Vegetation Science 29: 521-531.

Wilcox, B.A., \& Murphy, D.D. 1985. Conservation Strategy: The Effects of Fragmentation on Extinction. The American Naturalist 125: 879-887.

Yaacobi, G., Ziv, Y., \& Rosenzweig, M.L. 2007. Habitat fragmentation may not matter to species diversity. Proceedings of the Royal Society B: Biological Sciences 274: 2409-2412.

Zuur, A.F., Ieno, E.N., Walker, N.J., Saveliev, A.A., \& Smith, G.M. (Eds.). 2009. Mixed effects models and extensions in ecology with R. Journal of Statistical Software 32: 574. 


\section{TABLES}

Table 1: Outputs from the best candidate model (see main text for the list of candidate models) for each of the two compiled datasets used to analyze the observed variation in the magnitude of the coefficient estimate or slope parameter of the $\log (\gamma)$ variable (i.e. the response variable) in the $\log$ ratio model (see Equation 1 in the main text) of the $\alpha \sim \gamma$ relationship (AGR): (1) $\alpha_{\mathrm{FS}+\mathrm{FG}} \sim \gamma_{\mathrm{FS}+\mathrm{FG}}$ $(\mathrm{n}=90) ;(2) \alpha_{\mathrm{FSorFG}} \sim \gamma_{\mathrm{FSorFG}}(\mathrm{n}=180)$. Linear mixed-effects models (LMMs) were used to relate the response variable against fragmentation level (frag: NF, SF, HF), spatial scale (scale: 1, 2, 3, 4), species type (sp: FS vs. FG) and all possible two-way interactions between all three explanatory variables (see the materials and methods section in the main text). Bold values are representing significant $(\mathrm{p}<0.05)$ effects. Grey cells show marginal and conditional R-squared values for each of the three best candidate models.

\begin{tabular}{|c|c|c|c|}
\hline \multicolumn{4}{|c|}{ (1) $\alpha_{\mathrm{FS}+\mathrm{FG}} \sim \gamma_{\mathrm{FS}+\mathrm{FG}}(\mathrm{n}=90)$} \\
\hline & Coeff. & $t$ & $p$ \\
\hline Intercept_NF & 0.042 & 0.303 & 0.761 \\
\hline frag_HF & -0.447 & -0.343 & $<0.001$ \\
\hline frag_SF & -0.102 & -0.781 & 0.434 \\
\hline scale & 0.029 & 0.56 & 0.575 \\
\hline$R^{2} m / R^{2} c$ & & & $0.129 / 0.129$ \\
\hline \multicolumn{4}{|c|}{ (2) $\alpha_{\mathrm{FS} / \mathrm{FG}} \sim \gamma_{\mathrm{FS} / \mathrm{FG}}\left[\alpha_{\mathrm{FS}} \sim \gamma_{\mathrm{FS}}(\mathbf{n}=90) \& \alpha_{\mathrm{FG}} \sim \gamma_{\mathrm{FG}}(n=90)\right](\mathbf{n}=180)$} \\
\hline & Coeff. & $t$ & $\boldsymbol{P}$ \\
\hline Intercept_NF\&FS & -0.172 & -1.001 & 0.306 \\
\hline frag_HF & -0.517 & -2.176 & 0.029 \\
\hline frag_SF & -0.689 & -2.897 & 0.003 \\
\hline$s p \_F G$ & -0.191 & -0.802 & 0.422 \\
\hline frag_HF:sp_FG & 0.748 & 2.225 & 0.026 \\
\hline frag_SF:Sp_FG & 0.583 & 2.923 & 0.003 \\
\hline$R^{2} \mathrm{~m} / \mathrm{R}^{2} \mathrm{c}$ & & & $0.173 / 0.173$ \\
\hline
\end{tabular}

This article is protected by copyright. All rights reserved 


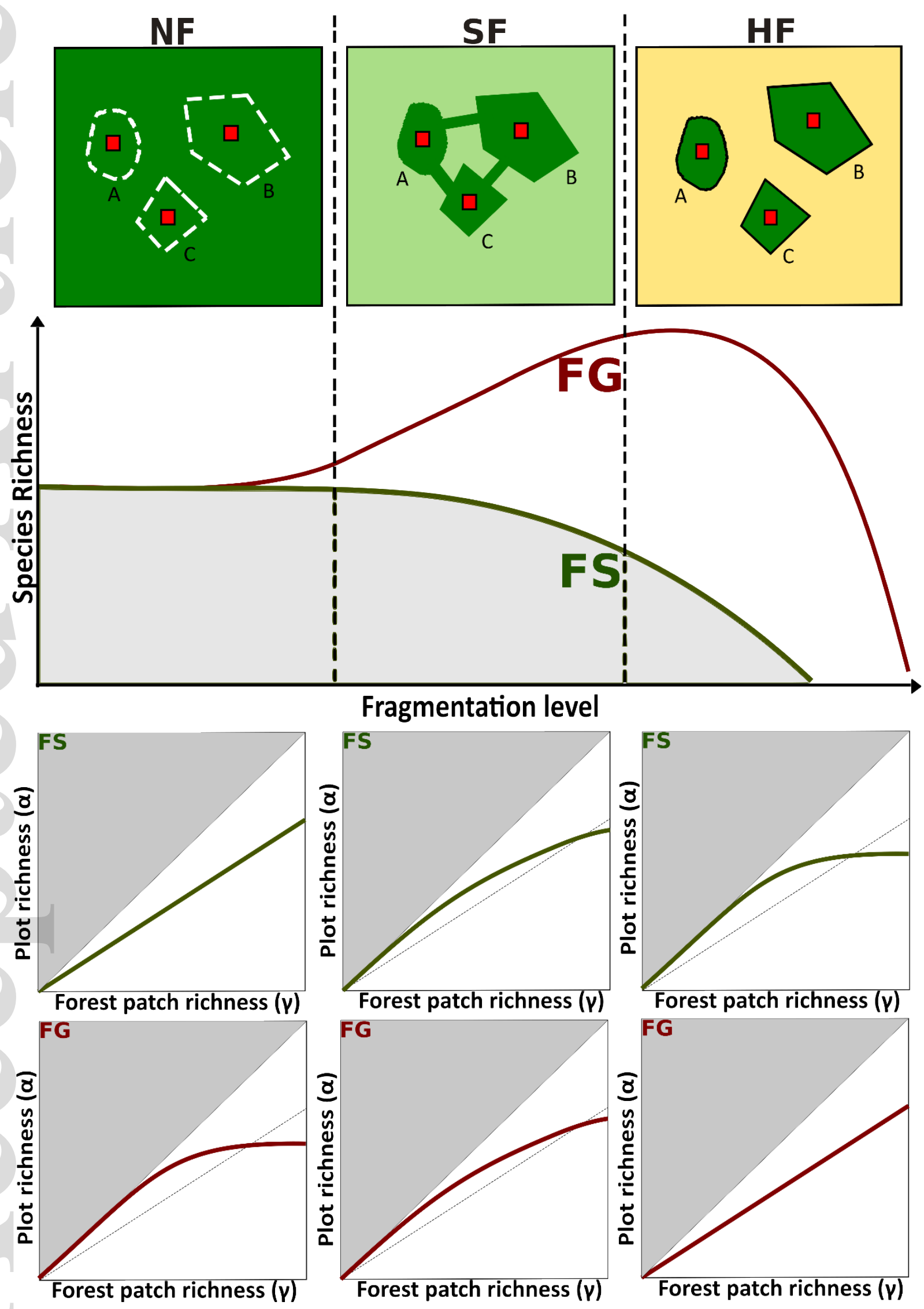


Figure 1: Schematic figure of the expected effect of forest fragmentation (none, intermediate and high) on the shape of the $\alpha \sim \gamma$ relationship (AGR) for forest specialists (FS) and generalists (FG). For FS in non-fragmented (NF) systems, we expect proportional sampling patterns (Type I) (i.e. $\alpha$-diversity increases linearly as $\gamma$-diversity increases) to predominate while in highly-fragmented (HF) systems, we expect FS to display a predominance of curvilinear-plateau patterns (Type II) (i.e. $\alpha$-diversity increases until reaching a plateau as $\gamma$-diversity increases). For FG, we expect the exact opposite situation as fragmentation increases. In the case of semi-fragmented (SF) systems, where both FS and FG species may locally co-occur, we expect intermediate or even indeterminate patterns to predominate for both FS and FG. For illustrative purpose, three forest patches (A, B and C), being connected or not by corridors (e.g. hedgerows), are depicted within three different types of matrices (forest, pastures with hedgerows, croplands). The less disturbed matrix is a forest matrix with continuous forest patches depicted by the white dotted lines while the most disturbed matrix is an agricultural landscape of croplands with forest patches being isolated from each other. The intermediate matrix is a matrix of pastures with forest patches being connected by hedgerows. The red squares inside the forest patches represent $\alpha$-diversity while the total patch area represents $\gamma$-diversity. 

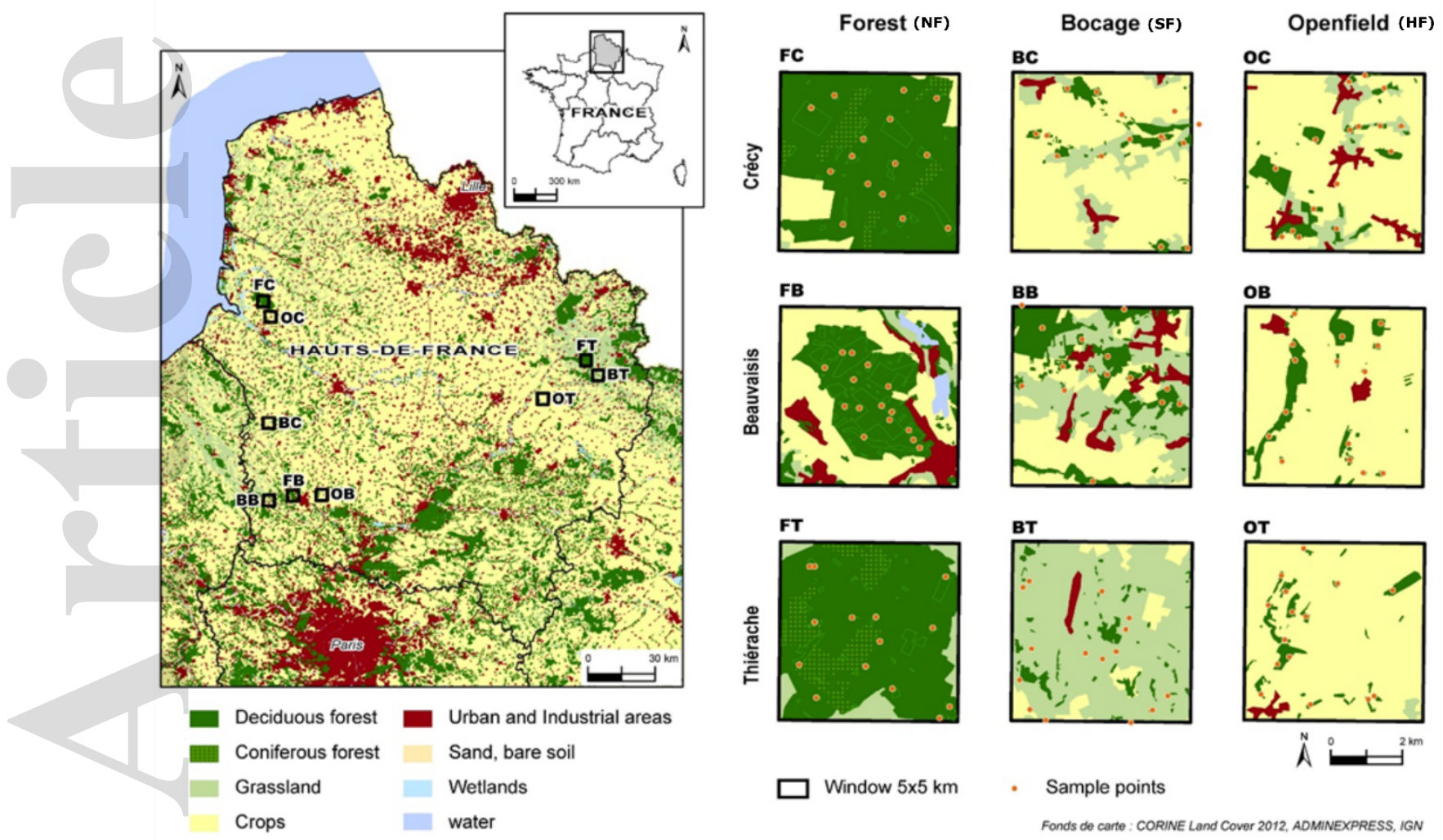

- Sample points

Fonds de carte : CORINE Land Cover 2012, ADMINEXPRESS, IGN

Figure 2: Map of the study area (northern France) covering three different regions (C: Ponthieu and Oise normande, B: Pays de Bray and Beauvaisis, T: Thiérache and Vermandois) with three different types of habitats (Forest, Bocage, Openfield), totaling nine landscape windows with 15 quadrats per window ( $\mathrm{n}=135$ quadrats). Each quadrat is a set of four spatial resolutions, in addition to total patch area, nested within each other: $1 \mathrm{~m}^{2} ; 10 \mathrm{~m}^{2} ; 100 \mathrm{~m}^{2} ;$ and $1000 \mathrm{~m}^{2}$. 
(a)

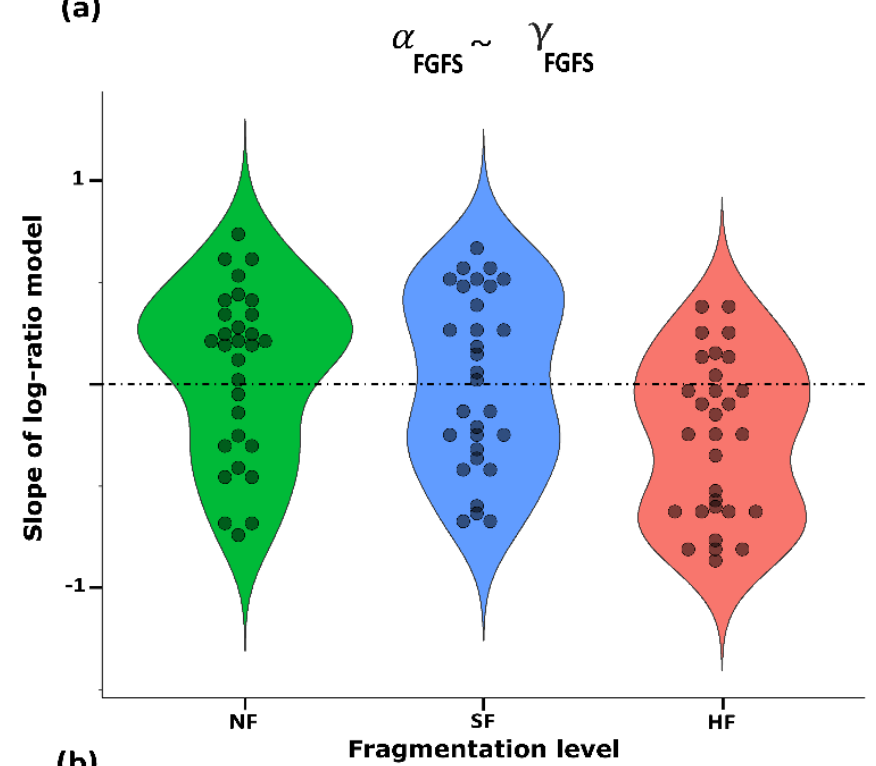

(b)

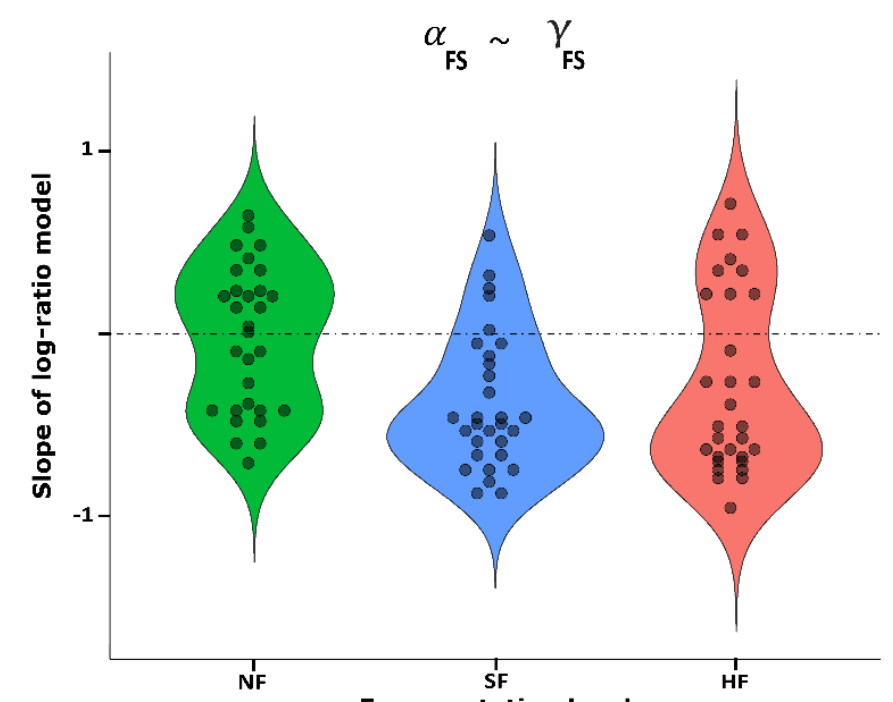

(c)

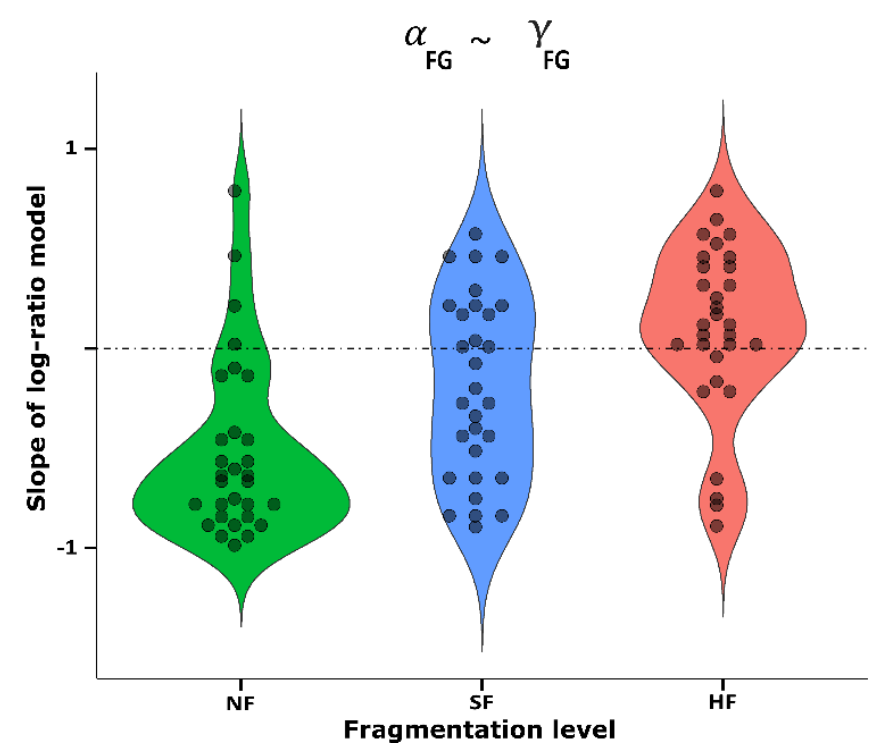

This article is protected by copyright. All rights reserved 
Figure 3: Variation in the distribution of the coefficient estimate or slope parameter of the $\log (\gamma)$ variable that we extracted from the log-ratio model (see Equation 1 in the main text) and that we used to quantitatively assess the shape of the $\alpha \sim \gamma$ relationship (AGR). Panel (a) represents the distribution of the slope parameter for the combined pool comprising both forest specialists and generalists $\left(\alpha_{\mathrm{FS}+\mathrm{FG}} \sim \gamma_{\mathrm{FS}+\mathrm{FG}}\right)$. Panels (b) and (c) represent the distribution of the slope parameter, separately, for forest specialists $\left(\alpha_{\mathrm{FS}} \sim \gamma_{\mathrm{FS}}\right)$ and generalists $\left(\alpha_{\mathrm{FG}} \sim \gamma_{\mathrm{FG}}\right)$, respectively. The FS, FG, $\mathrm{NF}$, SF and HF acronyms refer to forest specialists, forest generalists, non-fragmented systems, semi-fragmented systems and highly-fragmented systems, respectively. Green, blue and red colors represent non-fragmented systems, semi-fragmented systems and highly fragmented systems, respectively. 
(a)

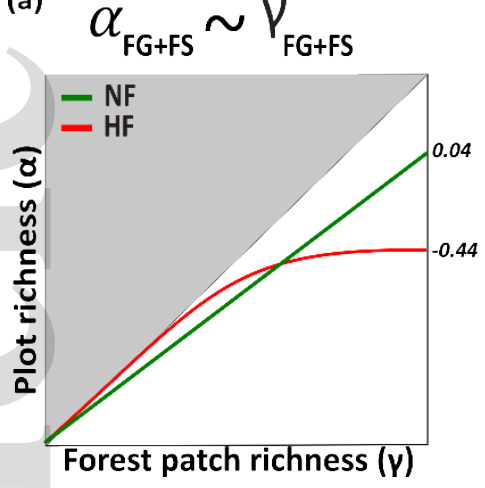

(b)

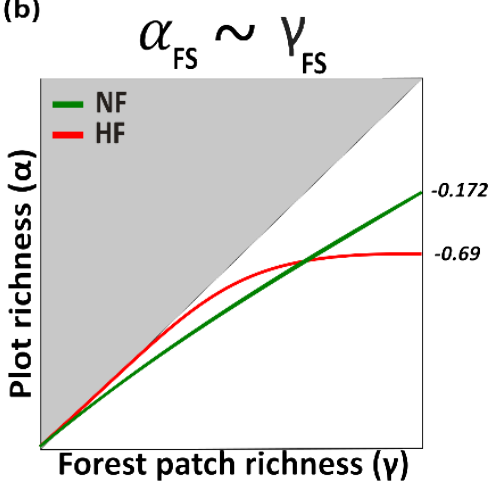

(c)

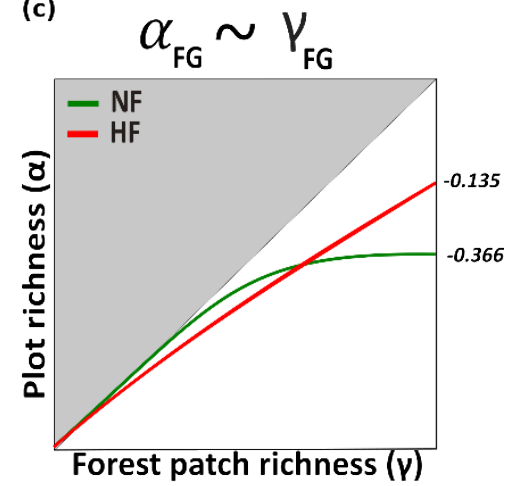

Figure 4: Changes in the $\alpha \sim \gamma$ relationship (AGR) as a function of fragmentation level. Panel (a) represents the AGR of the combined pool comprising both forest specialists and generalists $\left(\alpha_{\mathrm{FS}+\mathrm{FG}} \sim \gamma_{\mathrm{FS}+\mathrm{FG}}\right)$ showing linear $($ slope $=0.04)$ and curvilinear-plateau (slope $\left.=-0.44\right)$ AGR in non- and highly-fragmented systems, respectively. Panels (b) and (c) represent the AGR for forest specialists $\left(\alpha_{\mathrm{FS}} \sim \gamma_{\mathrm{FS}}\right)$ and generalists $\left(\alpha_{\mathrm{FG}} \sim \gamma_{\mathrm{FG}}\right)$, separately, with opposite patterns between the two guilds when shifting from non- to highly-fragmented systems. The FS, FG, NF and HF acronyms refer to forest specialists, forest generalists, non-fragmented systems and highly fragmented systems, respectively. Colors and drawings in Figure 5 (i.e. main results) mirror those used

in

Figure
4. 
Supporting information to the paper

Almoussawi. et al. Forest fragmentation shapes the alpha-gamma relationship in plant diversity. Journal of Vegetation Science.

Appendix S1: Data table (raw data) used in the log-ratio model showing the species richness.

Supporting information to the paper

Almoussawi. et al. Forest fragmentation shapes the alpha-gamma relationship in plant diversity. Journal of Vegetation Science.

Appendix S2: Species list.

Supporting information to the paper

Almoussawi. et al. Forest fragmentation shapes the alpha-gamma relationship in plant diversity. Journal of Vegetation Science.

Appendix S3: Description of the covariates used in the log-ratio models.

Supporting information to the paper

Almoussawi. et al. Forest fragmentation shapes the alpha-gamma relationship in plant diversity. Journal of Vegetation Science.

Appendix S4: Detailed description of the log-ratio model.

Supporting information to the paper

Almoussawi. et al. Forest fragmentation shapes the alpha-gamma relationship in plant diversity. Journal of Vegetation Science.

Appendix S5: One sample t-test for the distribution of the 270 slope values \& Anova outputs.

Supporting information to the paper

Almoussawi. et al. Forest fragmentation shapes the alpha-gamma relationship in plant diversity. Journal of Vegetation Science.

Appendix S6: Based on the coefficient estimate or slope parameter of the $\log (\gamma)$ variable, the $\alpha \sim$ $\gamma$ relationship (AGR) was classified into four types (I, II, INT, IND) for each of the three levels of fragmentation we tested. 
Supporting information to the paper

Almoussawi. et al. Forest fragmentation shapes the alpha-gamma relationship in plant diversity. Journal of Vegetation Science.

Appendix S7: Outputs from all candidate models.

Supporting information to the paper

Almoussawi. et al. Forest fragmentation shapes the alpha-gamma relationship in plant diversity.

Journal of Vegetation Science.

Appendix S8: Detailed outputs of two studied cases in the log-ratio models of $\alpha_{\mathrm{FS}} \sim \gamma_{\mathrm{FS}}$. 